Check for updates

Cite this: RSC Adv., 2019, 9, 40146

\title{
Liquid amphiphilic polymer for effective airborne dust suppression $\uparrow$
}

\author{
Taehee Lee, (D) a Junhyeok Park, (DD ${ }^{\mathrm{b}}$ David S. Knoff, (D) ${ }^{\mathrm{c}}$ Kwangmin Kim (D) ${ }^{\mathrm{b}}$ \\ and Minkyu Kim (D) *acd
}

Airborne dust is a byproduct of natural and artificial occurrences, including high winds in arid regions and human activities, and it affects most of the world's population. Watering is the most general practice for reducing airborne dust by wetting the surface of the dust source to agglomerate dust particles via the capillary effect, increasing the aerodynamic diameter of (ultra)fine particles and reducing dust emission. However, the short-term effectiveness due to fast water evaporation, requiring frequent watering, is a major disadvantage. Herein, we utilized biocompatible liquid polymers as additives in water to prolong moist conditions of dust sources due to their liquid state. After the water evaporated, the liquid polymers maintained moisture on the dust sources, resulting in significantly reduced (ultra)fine particle emissions and extended effectiveness compared to conventional water treatment. Interestingly, we observed greater dust suppressive effectiveness with liquid amphiphilic polymer than liquid hydrophilic polymer because of the synergistic effect of the liquid state and amphiphilic property of the polymer. Translating lab-scale experiments to pilot-scale field-testing confirmed the potential for utilizing biocompatible liquid amphiphilic polymers to advance airborne dust suppression technology.

Received 27th August 2019

Accepted 8th November 2019

DOI: $10.1039 / c 9 r a 06787 f$

rsc.li/rsc-advances industries, such as mining and construction. ${ }^{10-12}$ The major disadvantage of watering is a short-term effectiveness due to unpredictable rapid water evaporation rates dependent on atmospheric conditions, leading to the development of dust suppressants to control dust emissions.

Dust suppressants have been used to effectively suppress dust emission from the surface of dust sources. ${ }^{13-16}$ Current dust suppressants can be classified as chemicals, chlorides, asphalt emulsions and polymer emulsions, which hold distinct advantages and disadvantages. Chemicals, such as organic liquids and surfactants, are useful to suppress hydrophobic dust (e.g. coal particles) but can be harmful to human health. ${ }^{17}$ Chlorides are highly hygroscopic and reduce dust generation from the ground but can contaminate surrounding fauna, flora and groundwater as well as raise maintenance costs over time due to the corrosion on vehicles and steel equipment. ${ }^{18,19}$ Asphalt and polymer emulsions prevent dust escaping from the ground by forming a coating layer on the surface, but the rigid layer can be destroyed by external factors such as natural wind or artificial movements, negating its protective effect. ${ }^{18}$ Moreover, some of their components are naturally non-degradable and impose potential health and environmental risks. ${ }^{20-22}$ Taken altogether, the development of environmentally-friendly and effective dust control methods is still an ongoing process.

We focused on extending moist conditions on dust sources and decided to utilize liquid polymers as additives in water to maintain dust suppression even after water evaporates. To the best of our knowledge, the use of liquid polymers for dust 
control is rare; therefore, this concept was tested by evaluating the dust suppressive effectiveness of commercially available liquid polymers. ${ }^{23,24}$ When selecting liquid polymers, we considered water solubility, liquid phase in ambient conditions, biocompatibility, and environmentally friendliness in order to readily apply this technology to current watering practices. These preconditions resulted in the selection of liquid amphiphilic poly(ethylene oxide- $b$-propylene oxide- $b$-ethylene oxide) (PEO-PPO-PEO) triblock copolymer and liquid hydrophilic polyethylene glycol (PEG), used in food, cosmetics, and pharmaceuticals..$^{23,25-30}$ In order to evaluate the dust suppressive ability of the selected liquid polymers, as airborne dust model, we used fine mineral particles (average particle size: $<100 \mu \mathrm{m}$ ), known as mine tailings. Tailings, byproducts left over after the separation process of valuable minerals from the gangue of milled ores during mining, are often mixed with water into a slurry and deposited into an open-air tailings storage facility (TSF) where airborne dust can arise from the dried surface, causing health issues in local communities. ${ }^{31}$ Lab-scale experiments and pilot-scale field-testing validated the utilization of liquid amphiphilic polymers for effective dust suppression, paving a promising new avenue for the next-generation of dust control technology.

\section{Results \& discussion}

To investigate the dust suppressive effectiveness of selected liquid polymers, PM10 and PM2.5 concentrations were measured while applying $20 \mathrm{~m} \mathrm{~s}^{-1}$ wind onto the dried sample bed (Fig. 1a). In the absence of polymers, PM10 and PM2.5 concentrations were detected as $792.4 \pm 106.78 \mu \mathrm{g} \mathrm{m}^{-3}$ and $376.5 \pm 89.17 \mu \mathrm{g} \mathrm{m}^{-3}$, both exceeding "Hazardous" levels (PM10 $>425 \mu \mathrm{g} \mathrm{m}^{-3}$; PM2.5 > $251 \mu \mathrm{g} \mathrm{m}^{-3}$ ) according to the air quality index (AQI) from the US Environmental Protection Agency. ${ }^{32}$ When liquid PEG aqueous solution was applied to the mineral dust, PM decreased compared to water alone, and further PM reduction occurred with increasing PEG concentrations (Fig. 1b). The sample bed treated by 7 v/v\% PEG aqueous solution, compared to using water alone, reduced PM10 by $87 \%$ $\left(101.4 \pm 21.52 \mu \mathrm{g} \mathrm{m}^{-3}\right)$ and PM2.5 by $86 \%\left(52.8 \pm 10.56 \mu \mathrm{g} \mathrm{m}^{-3}\right)$ which indicated an AQI level of "Moderate" $\left(<154 \mu \mathrm{g} \mathrm{m}^{-3}\right)$ in PM10 and "Unhealthy for Sensitive Groups" $\left(<65.4 \mu \mathrm{g} \mathrm{m}^{-3}\right)$ in PM2.5. Since increasing liquid PEG concentrations reduced airborne PMs linearly (adjusted $R$-squared $=0.99$ in Table $\mathrm{S} 2 \dagger$ ), we confirmed that enhanced moist conditions due to the liquid state of polymers at dust sources effectively suppressed airborne dust.

Increasing PEO-PPO-PEO concentrations, on the other hand, did not linearly (adjusted $R$-squared $=-0.21$ in Table $\mathrm{S} 2 \dagger$ ) improve dust suppression as observed with PEG (Fig. 1c). When $1 \mathrm{v} / \mathrm{v} \%$ liquid PEO-PPO-PEO aqueous solution was applied to the mineral dust, PMs were suppressed by $80 \%$ compared to using water alone. PM10 and PM2.5 concentrations reduced further by $91 \%$ and $89 \%$, respectively, with $3 \mathrm{v} / \mathrm{v} \%$ of PEO-PPO-PEO while a statistically similar dust suppressive ability was observed at $5 \mathrm{v} / \mathrm{v} \%$. However, it was unexpected that
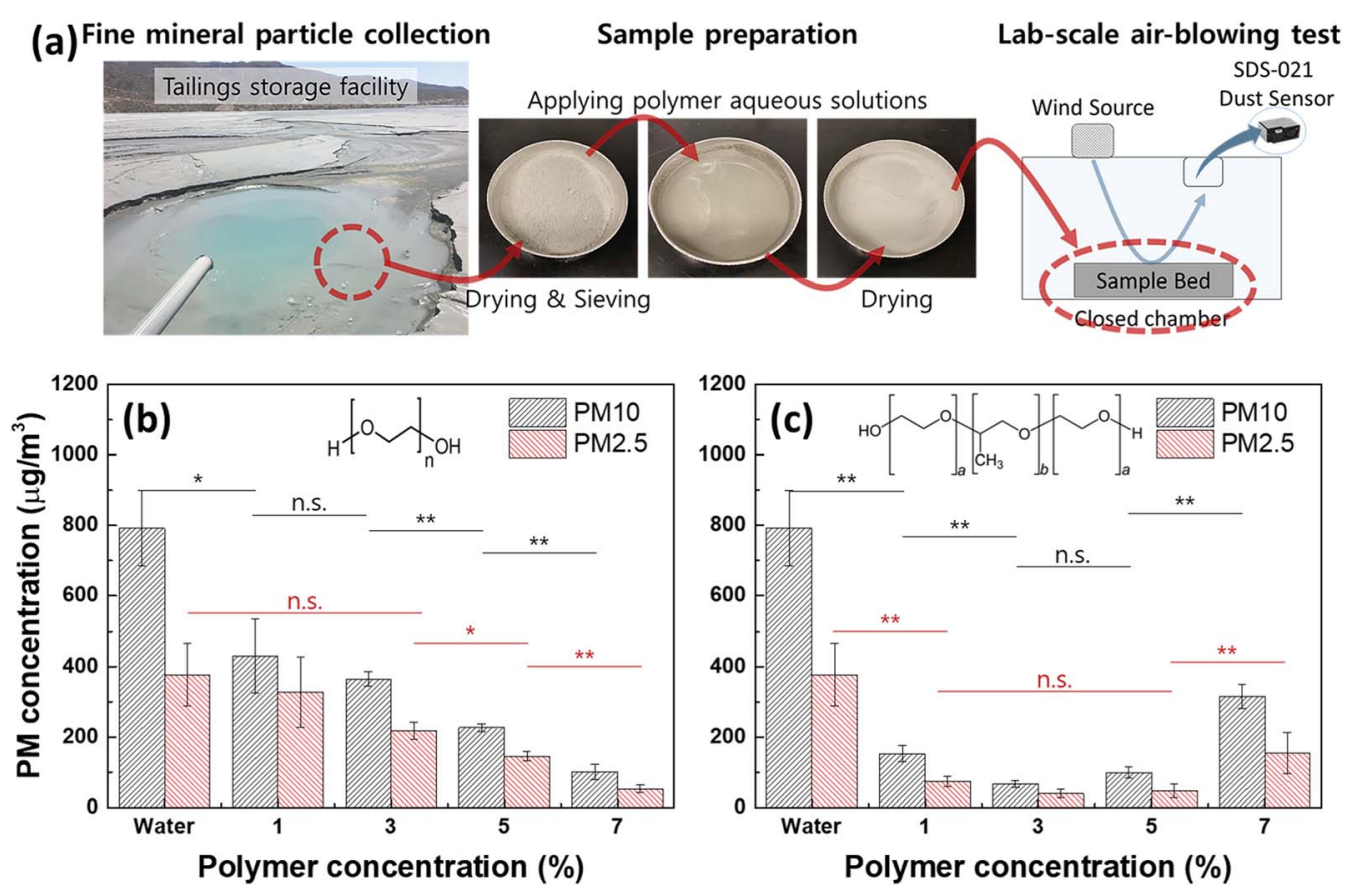

Fig. 1 Dust suppressive effectiveness of liquid polymers on (ultra)fine mineral particles. (a) The process of dust sample collection, preparation and lab-scale PM concentration measurement using homemade air-blowing tester (wind speed on the sample surface: $20 \mathrm{~m} \mathrm{~s}{ }^{-1}$ ).; (b) and (c) PM10 and PM2.5 concentrations measured from the sample beds treated by (b) 1-7 v/v\% of liquid PEG and (c) liquid PEO-PPO-PEO aqueous solutions. Insets in (b) and (c) are chemical structures of PEG polymer $(n=5)$ and PEO-PPO-PEO polymer $(a=8, b=32)$. A one-way analysis of variance (ANOVA) determined significant differences in PM concentrations between conditions (Table S1 $\dagger$ ). (note: $n=3 ; p$-value $\leq 0.05$ and $\leq$ 0.01 are denoted as * and **, respectively; n.s.: not significant). 
increasing PEO-PPO-PEO concentration to $7 \mathrm{v} / \mathrm{v} \%$ negatively influenced the PM concentrations, indicating an optimal concentration range of the liquid amphiphilic polymer for effective dust suppression. To understand the unexpected result by the liquid amphiphilic polymer at high concentrations, polymer aqueous solutions were prepared by diluting either liquid PEG or PEO-PPO-PEO polymers at $50 \mathrm{v} / \mathrm{v} \%$ in water and mixed mineral particles at a $1: 1 \mathrm{w} / \mathrm{v}$ ratio with each aqueous solution, then dried at room temperature for two weeks. Throughout the inversion test, PEG maintained its liquid state in a mixture with the mineral particles (Fig. S1a, ESI $\dagger$ ), describing the reason airborne PMs decreased linearly with escalating liquid PEG concentrations (Fig. 1b). Conversely, liquid PEO-PPO-PEO was separated from the particles and turned into a gel (Fig. S1b, ESI $\dagger$ ). The water solubility of the PEO-PPO-PEO is around $10 \%$ at $25{ }^{\circ} \mathrm{C},{ }^{30}$ but together with mineral particles, its water solubility could be decreased, causing the heterogeneous distribution of the polymer from the particles. This phase separation may inhibit dust suppression at relatively higher polymer concentrations (Fig. $1 \mathrm{c}$ and $\mathrm{S} 1 \dagger$ ).

The dust suppressive ability of liquid PEO-PPO-PEO polymer was superior to liquid PEG polymer at a low volume ratio in water (e.g. $3 \mathrm{v} / \mathrm{v} \%$ in Fig. $1 \mathrm{~b}$ and c). The optical microscope images show that both liquid polymers moistened and agglomerated mineral particles after water evaporation, while mineral particles treated by water alone reverted to the initial dried particles (Fig. 2). Moreover, the surface morphologies of mineral particles show that both liquid polymers increased the size of mineral particles compared to the sample treated by water alone (Fig. S2a-c, ESI $\dagger$ ). These results confirmed the concept, maintaining moist conditions of dust sources by liquid polymers, is advantageous for effective dust control in general (Fig. 1). However, this could not explain the greater dust suppression by liquid PEO-PPO-PEO polymer compared to liquid PEG polymer at low concentrations. Both liquid polymers share the same chemical backbone and polar hydroxyl side chains except for the nonpolar methyl side chains in the PPO mid-block of PEO-PPO-PEO polymers, which produce the amphiphilic property (insets of Fig. 1b and c). We speculated that this amphiphilic nature could explain the enhanced dust suppression.
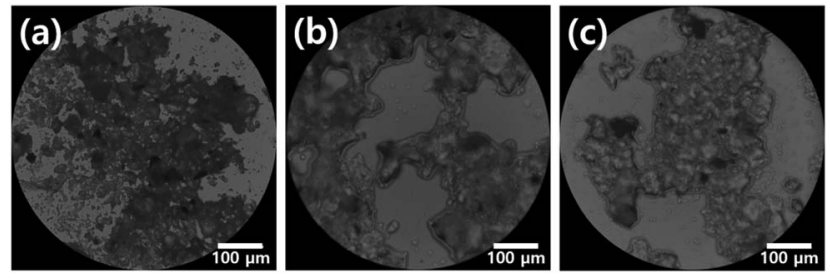

Fig. 2 Dust sample morphology of the mineral particles treated by water or polymer aqueous solutions. Mineral particles were mixed with the $1: 1 \mathrm{w} / \mathrm{v} \%$ of (a) water, (b) liquid PEG (3 v/v\%) and (c) liquid PEOPPO-PEO (3 v/v\%) aqueous solutions. Each $20 \mu \mathrm{L}$ of mixture was spotted on microscope glass slides and dried in an electric oven at $50{ }^{\circ} \mathrm{C}$ for a week before observation under an optical microscope.
To identify whether the amphiphilic property enhanced PM suppression, ATR-FTIR spectroscopy was performed to observe potential chemical information changes of mineral particles in the presence and absence of polymers (Fig. 3). Mineral particles presented main transmittance peaks at $1018 \mathrm{~cm}^{-1}$ and $1446 \mathrm{~cm}^{-1}$ wavenumbers, corresponding to $\mathrm{Si}-\mathrm{O}$ vibration and $\mathrm{CO}_{3}$ stretch (black solid lines in Fig. 3e-h). ${ }^{33}$ With increasing liquid PEG concentrations, the intensity of mineral particle spectrum was continuously weakened (Fig. 3e). Similar to the PEG result, the intensity of mineral particles decreased when treated by $1 \mathrm{v} / \mathrm{v} \%$ of PEO-PPO-PEO polymer (red solid lines in Fig. 3f). However, when the PEO-PPO-PEO concentration increased to $3 \mathrm{v} / \mathrm{v} \%$, a new peak at $1132 \mathrm{~cm}^{-1}$ clearly appeared and, at $5 \mathrm{v} / \mathrm{v} \%$, distinct PEO-PPO-PEO polymer peaks were detected at $1108 \mathrm{~cm}^{-1}, 1369 \mathrm{~cm}^{-1}, 2871 \mathrm{~cm}^{-1}$, and $2979 \mathrm{~cm}^{-1}$ (Fig. 3b, f, S3b and S4b, ESI $\dagger$ ). ${ }^{34,35}$ The new peak was not observable in spectrums of the dust particles or liquid polymers alone. Therefore, we speculated that the peak was the resultant of molecular interactions between mineral particles and PEOPPO-PEO polymers, specifically caused by the PPO block.

To investigate whether the new peak at $1132 \mathrm{~cm}^{-1}$ was from the molecular interaction, the spectrum of mineral particles was analyzed with only liquid polypropylene glycol (PPG) polymer. When increasing PPG concentrations from $1 \mathrm{v} / \mathrm{v} \%$, the main IR peaks of the particles at $1018 \mathrm{~cm}^{-1}$ and $1446 \mathrm{~cm}^{-1}$ reduced (Fig. 3g), similar to the results from liquid PEG. Distinct PPG peaks at $1100 \mathrm{~cm}^{-1}, 1371 \mathrm{~cm}^{-1}, 2869 \mathrm{~cm}^{-1}$, and $2981 \mathrm{~cm}^{-1}$ appeared at $3 \mathrm{v} / \mathrm{v} \%$, similar to the spectrum of mineral particles with more than $5 \mathrm{v} / \mathrm{v} \%$ of PEO-PPO-PEO (Fig. 3c, g, S3c and S4c, ESI $\dagger$ ). ${ }^{36}$ However, the new peak at $1132 \mathrm{~cm}^{-1}$ in Fig. 3d was not detectable, indicating the peak cannot be explained by the PPO block alone.

To conclude whether the peak at $1132 \mathrm{~cm}^{-1}$ is a unique feature or a common feature of any PEO-PPO-PEO polymers in the mixture with mineral particles, the polymer in solid state was also investigated. Similar to the spectrum of mineral particles mixed with liquid PEG, the intensity gradually reduced with increasing concentrations of solid PEO-PPO-PEO without any additional peaks (Fig. $3 \mathrm{~h}$ ). Therefore, we conclude that the peak at $1132 \mathrm{~cm}^{-1}$ is a distinguished feature from the mixture of mineral particles and liquid PEO-PPO-PEO polymer.

Assuming the peak was caused by molecular interaction, it was hypothesized that the molecular interaction was responsible for the improvement in dust suppression with liquid PEOPPO-PEO. After confirming that liquid PEO-PPO-PEO polymer controls airborne dust better than liquid PEG polymer (Fig. 1b and c), dust suppressive effectiveness was investigated by applying liquid PPG and solid PEO-PPO-PEO polymers. Compared to water alone, PM10 and PM2.5 concentrations were significantly reduced by both liquid PPG and solid PEO-PPOPEO. At 3-5 v/v\%, sample beds treated by both polymers reduced the PM10 and PM2.5 by $64-78 \%$ (Fig. S5, ESI $\dagger$ ). Both polymers were more effective than liquid PEG at suppressing dust at $3 \mathrm{v} / \mathrm{v} \%$, but performed comparably at $5 \mathrm{v} / \mathrm{v} \%$ (Fig. 1b). Still, at the same concentration range liquid PEO-PPO-PEO had superior PM suppression compared to liquid PPG and solid PEO-PPO-PEO by $45-70 \%$. Therefore, we concluded that the 

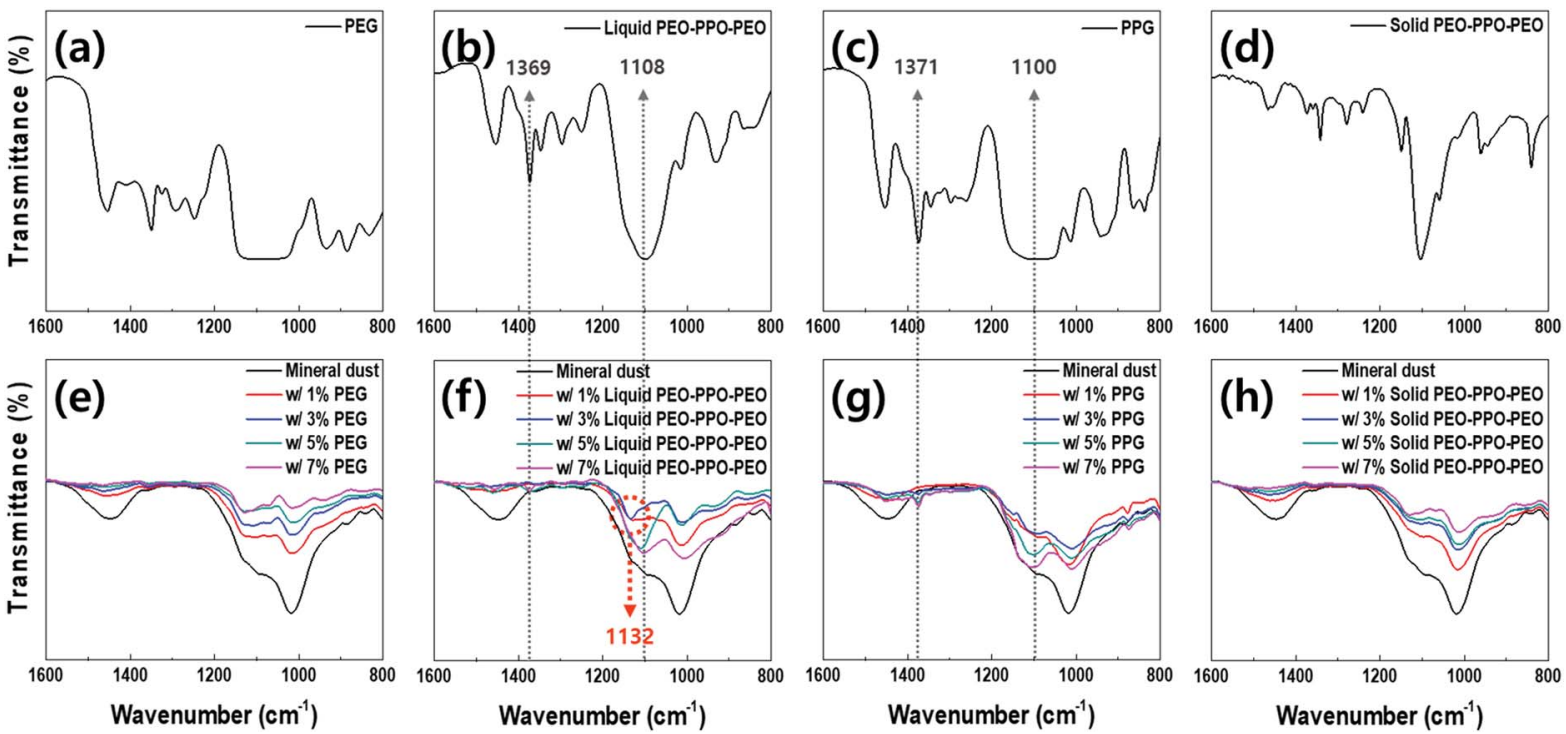

Fig. 3 ATR-FTIR spectrums of (a) liquid PEG, (b) liquid PEO-PPO-PEO, (c) liquid PPG and (d) solid PEO-PPO-PEO polymers and mineral dust mixed at $1: 1 \mathrm{w} / \mathrm{v}$ ratio with polymer aqueous solutions of (e) liquid PEG (1-7 v/v\%), (f) liquid PEO-PPO-PEO (1-7 v/v\%), (g) liquid PPG (1-7 v/v\%) and $(\mathrm{h})$ solid PEO-PPO-PEO (1-7 w/v\%). All samples were dried in electric oven at $50{ }^{\circ} \mathrm{C}$ for a week. The black solid lines in (e)-(h) represent the mineral particles treated by water alone.

enhanced dust suppression by the liquid amphiphilic polymer (Fig. 1c) is caused by not only increased moist conditions at dust sources by its liquid state (Fig. 2), but also the molecular interaction between mineral particles and the liquid PEO-PPOPEO polymer (Fig. 3f).

Pilot-scale testing was performed to demonstrate the dust suppressive ability of the liquid amphiphilic polymer at a local mine. At an inactive TSF, each testing bed was prepared (Fig. S6a, ESI $\dagger$ ). Dust mixtures with water or $5 \mathrm{v} / \mathrm{v} \%$ polymer aqueous solutions were poured on the top of testing beds and then dried for two weeks in ambient conditions (Fig. S6b, ESI†). To mimic the maximum wind speed recorded at the field site, $10 \mathrm{~m} \mathrm{~s}^{-1}$ wind was applied to measure PM concentrations (Fig. S6c, ESI $\dagger$ ). Compared to the lab-scale testing (Fig. 1), PMs were generally detected at higher concentrations, potentially caused by uncontrollable dust influx from the large untreated areas outside of the testing beds over the two-week testing period because smaller dust particles than the $53 \mu \mathrm{m}$ hole size can pass through the fabric mesh screens (US standard 270 mesh). Before the air-blowing test, dust layers were observed on top of each testing bed. However, the tests were performed without cleaning up the dust layers in order to avoid introducing human error. This situation indicated the dust influx for a drying process for two weeks can cause higher dust concentration in the field testing than that in the lab-scale testing (Fig. S6d, ESI $\dagger$ ). When PM concentrations were compared between testing beds, the water-treated testing bed generated PM10 of $1236.8 \pm 426.97 \mu \mathrm{g} \mathrm{m}^{-3}$ and PM2.5 of $279.6 \pm 136.28$ $\mu \mathrm{g} \mathrm{m}{ }^{-3}$, while the testing bed treated by liquid PEG aqueous solution reduced PM10 by $53 \%$ and PM 2.5 by $58 \%$ compared to water alone. When liquid PEO-PPO-PEO aqueous solution was applied, PM10 and PM2.5 were decreased by $86 \%$ and $92 \%$, compared to water alone. Interestingly, the liquid PEO-PPO-
PEO reduced crack formations on the surface of testing beds, possibly caused by the molecular interactions between the polymer and particles, contributing to the dust reduction (Fig. S6e, ESI $\dagger$ ). Altogether, effective airborne dust suppression was identified as a result of both the liquid phase that maintains moist conditions at dust sources and the molecular interactions that potentially reduced crack formations on the surfaces.

\section{Conclusions}

The use of liquid amphiphilic PEO-PPO-PEO polymer at low v/ v\% with water effectively suppressed PM10 and PM2.5 compared to all testing conditions, including water alone, liquid PEG, liquid PPG, and solid PEO-PPO-PEO polymers. The polymer aqueous solutions are readily adaptable to general water spraying systems because of similar viscosity values with that of pure water $\left(1 \mathrm{mPa} \mathrm{s}\right.$ at $20^{\circ} \mathrm{C}$; Fig. S7, ESI $\left.\dagger\right)$ and as demonstrated during field-scale testing at a mine operation. ${ }^{37}$ Furthermore, when considering that the amount of sunshine, especially UVA, is about $8-12 \mathrm{~h}$ per day, the half-life of the polymer was 4-6 months (Fig. S8, ESI $\dagger$ ). Therefore, applying environmentally friendly, readily adaptable, degradable, liquid amphiphilic PEO-PPO-PEO polymer is a novel strategy for the mitigation of airborne dust emission from naturally occurring sources and artificial industrial byproducts.

\section{Materials and methods}

Fine mineral particles were obtained from a local mine in Arizona, USA. The mineral particles mainly consisted of $\mathrm{Si}, \mathrm{Ca}, \mathrm{Al}$, and Fe atoms and most of them were in the complex oxides and sulfides (Fig. S9, ESI $\dagger$ ). Polymer aqueous solutions were 
prepared by the addition of polymers in deionized (DI) water at 1-7 v/v\% (polymer information are described in the ESI $\dagger$ ). Sample beds consisted of mineral particles damped by each polymer aqueous solution, then dried for a week.

The air-blowing tests were carried out with $20 \mathrm{~m} \mathrm{~s}^{-1}$ and $10 \mathrm{~m} \mathrm{~s}^{-1}$ wind in the lab and field tests, respectively, approximately twice as strong as the strongest wind $\left(12 \mathrm{~m} \mathrm{~s}^{-1}\right)$ since 2010 at the pilot-scale field testing site. PM10 and PM2.5 concentrations were monitored using a laser dust sensor and recorded using a Raspberry Pi. Maximum values were collected in each PM measurement for the calculation of averages and standard deviations. Statistical data analysis was carried out using Origin Lab software.

Polymer characteristics, microstructure analysis and element analysis of mineral particles alone or together with polymers were performed using Attenuated Total ReflectanceFourier Transform Infrared (ATR-FTIR) spectroscopy, optical microscopy, matrix assisted laser desorption ionization-time of flight mass spectrometry (MALDI-TOF MS) and Scanning Electron Microscope-Energy Dispersive X-ray Spectroscopy (SEMEDS). More details are described in the ESI. $\dagger$

\section{Conflicts of interest}

M. K. and K. K. are inventors on a pending US patent application (PCT/US2018/055466; assigned to the University of Arizona), regarding the use of liquid polymers for airborne dust control. M. K. is a Chief Scientific Advisor for Clean Earth Tech. Otherwise, the authors declare no competing financial interests.

\section{Acknowledgements}

This work was supported by Tech Launch Arizona at the University of Arizona (UA17-240; TL, JP, KK and MK) and the National Heart, Lung, and Blood Institute of the National Institutes of Health (T32 HL007955; DSK). The content is solely the responsibility of the authors and does not necessarily represent the official views of the National Institutes of Health.

\section{References}

1 World Health Organization, Ambient air pollution: A global assessment of exposure and burden of disease, 2016.

2 E. Kalisa, E. G. Nagato, E. Bizuru, K. C. Lee, N. Tang, S. B. Pointing, K. Hayakawa, S. D. J. Archer and D. C. Lacap-bugler, Environ. Sci. Technol., 2018, 52, 1217912187.

3 A. G. Miguel, G. R. Cass, M. M. Glovsky and J. Weiss, Environ. Sci. Technol., 1999, 33, 4159-4168.

4 K.-H. Kim, E. Kabir and S. Kabir, Environ. Int., 2015, 74, 136143.

5 A. G. Russell and B. Brunekreef, Environ. Sci. Technol., 2009, 43, 4620-4625.

6 D. E. Schraufnagel, J. R. Balmes, C. T. Cowl, S. De Matteis, S. H. Jung, K. Mortimer, R. Perez-Padilla, M. B. Rice,
H. Riojas-Rodriguez, A. Sood, G. D. Thurston, T. To, A. Vanker and D. J. Wuebbles, Chest, 2019, 155, 409-416.

7 P. K. Rai, Ecotoxicol. Environ. Saf., 2016, 129, 120-136.

8 P. Žalud, J. Száková, J. Sysalová and P. Tlustoš, Cent. Eur. J. Biol., 2012, 7, 519-530.

9 J. Tremlová, J. Száková, J. Sysalová and P. Tlustoš, J. Sci. Food Agric., 2013, 93, 1378-1384.

10 Z. Sui, T. Wang, Y. Peng, W.-P. Pan, P. Norris and Y. Zhang, Fuel, 2018, 238, 430-439.

11 L. Cheng, Ind. Eng. Chem. Process Des. Dev., 1973, 12, 221225.

12 J. S. Kinsey and C. Cowherd, J. Air Waste Manage. Assoc., 2005, 55, 772-783.

13 F. Amato, A. Karanasiou, P. Cordoba, A. Alastuey, T. Moreno, F. Lucarelli, S. Nava, G. Calzolai and X. Querol, Environ. Sci. Technol., 2014, 48, 8069-8077.

14 H. W. Zeller, Laboratory Tests for Selecting Wetting Agents for Coal Dust Control, RI8815, 1983.

15 F. N. Kissell, Handbook for Dust Control in Mining, Department of Health and Human Services, DHHS (NIOSH) Publication No. 2003-147, 2006.

16 A. B. Cecala, A. D. O'Brien, J. Schall, J. F. Colinet, W. R. Fox, R. J. Franta, J. Joy, W. R. Reed, P. W. Reeser, J. R. Rounds and M. J. Schultz, Dust Control Handbook for Industrial Minerals Mining and Processing, Department of Health and Human Services, DHHS (NIOSH) Publication No. 2012-112, 2012.

17 T. Ivanković and J. Hrenović, Arh. Hig. Rada Toksikol., 2010, 61, 95-110.

18 T. C. Piechota, J. van Ee, J. R. Batista, K. A. Stave and D. E. James, Potential Environmental Impacts of Dust Suppressants: 'Avoiding Another Times Beach', Environmental Protection Agency, EPA/600/R-04/031, 2004.

19 A. Tiwari and J. W. Rachlin, Northeast. Nat., 2018, 25, 123142.

20 E. A. Smith, S. L. Prues and F. W. Oehme, Ecotoxicol. Environ. Saf., 1996, 35, 121-135.

21 L. Lépine and R. Gilbert, Polym. Degrad. Stab., 2002, 75, 337345.

22 D. Lešinský, J. Fritz and R. Braun, Bioresour. Technol., 2005, 96, 197-201.

23 N. Suthiwangcharoen and R. Nagarajan, in Methods in Enzymology, Elsevier Inc., 2017, vol. 590, pp. 277-304.

24 M. Kim, M. Gkikas, A. Huang, J. W. Kang, N. Suthiwangcharoen, R. Nagarajan and B. D. Olsen, Chem. Commun., 2014, 50, 5345-5348.

25 P. Alexandridis and T. A. Hatton, Colloids Surf., A, 1995, 96, 1-46.

26 M. Younes, P. Aggett, F. Aguilar, R. Crebelli, B. Dusemund, M. Filipič, M. J. Frutos, P. Galtier, D. Gott, U. GundertRemy, G. G. Kuhnle, C. Lambré, I. T. Lillegaard, P. Moldeus, A. Mortensen, A. Oskarsson, I. Stankovic, I. Waalkens-Berendsen, R. A. Woutersen, M. Wright, P. Boon, O. Lindtner, C. Tlustos, A. Tard and J. C. Leblanc, EFSA J., 2018, 16, 1-17.

27 F. M. Veronese, PEGylated protein drugs: Basic Science and Clinical Applications, Milestones in Drug Therapy, Boston, 2009. 
28 F. E. Bailey and J. V. Koleske, in Poly (ethylene Oxide), Academic Press, New York, 1976, pp. 163-169.

29 H. Shane, Handbook of Pharmaceutical Excipients: Pharmaceutical Excipients, Pharmaceutical Press and American Pharmacists Association, London, Sixth, 2009.

30 S. D. Singh-Joy and V. C. McLain, Internet J. Toxicol., 2008, 27, 93-128.

31 J. Csavina, J. Field, M. P. Taylor, S. Gao, A. Landázuri, E. A. Betterton and A. E. Sáez, Sci. Total Environ., 2012, 433, 58-73.

32 E. K. Cairncross, J. John and M. Zunckel, Atmos. Environ., 2007, 41, 8442-8454.
33 Z. Hao, H. A. Bechtel, T. Kneafsey, B. Gilbert and P. S. Nico, Sci. Rep., 2018, 8, 2552.

34 M. Vandenhaute, J. Schelfhout, S. Van Vlierberghe, E. Mendes and P. Dubruel, Eur. Polym. J., 2014, 53, 126-138.

35 G. Zhou, T. Fan and Y. Ma, J. Chem. Technol. Biotechnol., 2017, 92, 2699-2708.

36 H. Shinzawa, T. Uchimaru, J. Mizukado and S. G. Kazarian, Vib. Spectrosc., 2017, 88, 49-55.

37 J. Park, K. Kim, T. Lee and M. Kim, Mining, Metallurgy \& Exploration, 2019, 36, 785-795. 